$11-1-2005$

\title{
A Nonrigorous Approach Of Incorporating Sensitizing Rules Into Multivariate Control Charts
}

Michael B. C. Khoo

Universiti Sains, Malaysia, mkbc@usm.my

Follow this and additional works at: http://digitalcommons.wayne.edu/jmasm

Part of the Applied Statistics Commons, Social and Behavioral Sciences Commons, and the Statistical Theory Commons

\section{Recommended Citation}

Khoo, Michael B. C. (2005) "A Nonrigorous Approach Of Incorporating Sensitizing Rules Into Multivariate Control Charts," Journal of Modern Applied Statistical Methods: Vol. 4 : Iss. 2 , Article 22.

DOI: $10.22237 /$ jmasm/1130804460

Available at: http://digitalcommons.wayne.edu/jmasm/vol4/iss2/22

This Regular Article is brought to you for free and open access by the Open Access Journals at DigitalCommons@WayneState. It has been accepted for inclusion in Journal of Modern Applied Statistical Methods by an authorized editor of DigitalCommons@WayneState. 


\title{
A Nonrigorous Approach Of Incorporating Sensitizing Rules Into Multivariate Control Charts
}

\author{
Michael B.C. Khoo \\ School of Mathematical Sciences \\ Universiti Sains Malaysia
}

Multivariate control charts are becoming more important in the monitoring of processes in manufacturing industries because the quality of a process is usually determined by several correlated variables (quality characteristics). The most popular multivariate process control procedure is based on the Hotelling control chart. It is used to monitor the mean vector of a process. A nonrigorous approach of using four sensitizing rules is introduced to improve the performance of a conventional Hotelling chart. The use of these rules on a conventional Hotelling chart do not require a transformation of the $T^{2}$ statistics into normal random variables. Thus, the $T^{2}$ statistics incorporating these rules can be plotted on the same scale as they are plotted on a Hotelling chart. Numerous SAS and Mathematica programs are given to aid quality control practitioners in implementing these rules in real life problems. The aim of this article is to make the implementation of sensitizing rules appealing and user friendly to practitioners.

Key Words: sensitizing rules; Hotelling; average run length (ARL); in-control; out-of-control (o.o.c.); Markov chain; upper control limit (UCL)

\section{Introduction}

Since its inception (Hotelling, 1947), numerous extensions have been made to the conventional Hotelling $T^{2}$ chart. Tracy, Young and Mason (1992) discussed an exact method based on the beta distribution for constructing multivariate control limits at the start-up stage. Timm (1996) introduced the use of a single step and stepdown finite intersection test (FIT) to evaluate whether a multivariate process is in-control or out-ofcontrol. Runger (1996) discussed an approach based on projections, which simplifies the construction and understanding of a multivariate Hotelling chart. A comparison of using various estimators of the covariance matrix for the Hotelling chart was made by Sullivan and Woodall (1996).

Michael B. C. Khoo is a Lecturer at the Universiti Sains Malaysia. His research interests are statistical process control and reliability analysis. He is a member of the editorial board of Quality Engineering.
Prins and Mader (1997) provided some interesting discussion on multivariate control charts for subgrouped data and individual observations. Key implementation and interpretation issues as well as assessing the problems that currently exist when using multivariate charts were examined by Mason, Champ, Tracy, Wierda and Young (1997). Aparisi (1997) proposed sampling plans for the multivariate $T^{2}$ control chart.

Various approaches in the identification of the problematic quality characteristics when the $T^{2}$ chart signals an o.o.c. are suggested in the literature. These include the works of Doganaksoy, Faltin and Tucker (1991), Holmes and Mergen (1995), Mason, Tracy and Young (1995; 1997), Runger, Alt and Montgomery (1996) and Nedumaran and Pignatiello (1998). Apley and Tsung (2002) investigated and provided guidelines for designing the autoregressive $T^{2}$ chart in the monitoring of univariate autocorrelated processes. The usefulness of the Hotelling $T^{2}$ statistic for the monitoring of batch processes in both Phase I and Phase II operations were shown in Mason, Chou and Young (2001). Vargas (2003) 
suggested $T^{2}$ charts based on robust estimators of location and dispersion using minimum volume ellipsoid (MVE) estimators, which are effective in detecting any reasonable number of outliers.

Sensitizing rules are supplementary criteria that are used to increase the sensitivity of a univariate control chart to small process shifts so that assignable causes can be detected quicker (Montgomery, 2001). Nelson (1984) provided a good discussion of some of these rules. Champ and Woodall (1987) studied the ARL performances of a univariate Shewhart chart with various sensitizing rules and found that the use of these rules improve the ability of the chart to detect smaller shifts at the expense of the Type-I error. To overcome this problem, Klein (2000) introduced two alternative schemes to the $\bar{X}$ chart, namely rules 2-of-2 and 2-of-3. The Type-I error of these two rules can be fixed by the user and then their respective limits are determined using a Markov chain approach.

One fundamental requirement of using sensitizing rules on a control chart is that the consecutive statistics plotted on the chart must be normally distributed. This is aside from the independent and identically distributed (i.i.d.) assumption of the sequence of control chart statistics. To meet the normality requirement, Khoo and Quah (2003) and Kooh, Quah, and Low (2004), suggested an approach of transforming the Hotelling statistic into a standard normal random variable prior to the application of different sensitizing rules on a multivariate chart. Their suggestion by means of transformation allows the use of such rules on the Hotelling control chart. Though their suggestion is a useful contribution to multivariate quality control, it has increased the complexity of using a Hotelling chart to a certain extent, which may make the suggested approach less appealing to some practitioners.

The main objective in this article is to solve the above problem by making the incorporation of sensitizing rules into a Hotelling chart user friendly so that quality control practitioners will find such enhancements useful in their work. Unlike the previous works of Khoo and Quah (2003) and Kooh, Quah, and Low (2004), the new approach suggested in this article does not require the transformation of a $T^{2}$ statistic into a standard normal random variable, hence it is referred to as a nonrigorous approach. Besides ease of implementation, another remarkable advantage of the new approach is that it allows the $T^{2}$ statistics to be plotted on their original scale on a Hotelling control chart. Thus, the use of the conventional Hotelling chart can still be maintained by drawing additional limits on the chart for the sensitizing rule being implemented.

SAS programs are provided for cases of $\mu$ and $\Sigma$ known and unknown, involving both individual measurements and subgrouped data. Now, practitioners can easily compute the limits of each of the four rules by running the SAS programs after entering the desired values of the required parameters.

The Conventional Hotelling $T^{2}$ Control Chart

In the monitoring of a multivariate process where the data belong to individual observations and follow a multivariate normal distribution, i.e., $\boldsymbol{X}_{i} \sim N_{p}(\mu, \Sigma), \mathrm{i}=1,2, \ldots$, the following $T^{2}$ statistics are used (Tracy, Young and Mason, 1992):

$T_{i}^{2}=\left(X_{i}-\mu\right)^{\prime} \Sigma^{-1}\left(X_{i}-\mu\right), i=1,2, \ldots$.

Here, $T_{i}^{2} \sim \chi_{p}^{2}$ where $p$ is the number of quality characteristics monitored simultaneously. For the case where both $\mu$ and $\Sigma$ are unknown, the equation below which is given in Tracy, Young and Mason (1992) is used:

$T_{f}^{2}=\left(X_{f}-\bar{X}_{m}\right)^{\prime} S_{m}^{-1}\left(X_{f}-\bar{X}_{m}\right), f=1,2, \ldots$.

It is shown in Tracy, Young and Mason (1992) that the exact distribution of $T_{f}^{2}$ is $T_{f}^{2}$ $\frac{p(m-1)(m+1)}{m(m-p)} F_{p, m-p}$, where $p$ is the number of quality characteristics, $m$ is the size of the stable reference sample, $\overline{\boldsymbol{X}}_{m}$ and $\boldsymbol{S}_{m}$ are estimates of the mean vector and covariance matrix from a stable reference sample of size $m$ respectively. $\boldsymbol{X}_{f}$ in equation (2) denotes a future multivariate 
normal $N_{p}(\mu, \Sigma)$ observation taken at time $f$, so that the state of a process at that time can be determined.

For subgrouped data, the test statistics plotted on the Hotelling $T^{2}$ chart are

$$
T_{j}^{2}=n\left(\bar{X}_{j}-\mu\right)^{\prime} \Sigma^{-1}\left(\bar{X}_{j}-\mu\right), \quad j=1,2, \ldots,
$$

where $j$ is the subgroup number. It is assumed that the joint probability distribution of the $p$ quality characteristics is the $p$-variate normal distribution. In equation (3), $\overline{\boldsymbol{X}}_{j}$ is a $p \times 1$ vector of sample means for each of the $p$ quality characteristics from a sample of size $n, \mu$ is a vector of in-control means for each of the $p$ quality characteristics and $\Sigma$ is the covariance matrix. It is noted in Montgomery (2001) that $T_{j}^{2} \sim \chi_{p}^{2}$. If both $\mu$ and $\Sigma$ are unknown, the estimates of these parameters are $\overline{\bar{X}}$ and $S$ respectively. Here, $\overline{\bar{X}}$ and $S$ are the sample grand mean vector and the sample covariance matrix estimated from an in-control preliminary data set whose formulas are given in Montgomery (2001).

There are two phases of control chart usage, namely phase 1 and phase 2 . Phase 1 is a stage where the chart is used for establishing control while in phase 2 , the chart is used to monitor a future production. It is shown in Montgomery (2001) that in phase $1, T_{j}^{2}$ $\frac{p(m-1)(n-1)}{m n-m-p+1} F_{p, m n-m-p+1}$ and in phase $2, T_{j}^{2} \sim$

$\frac{p(m+1)(n-1)}{m n-m-p+1} F_{p, m n-m-p+1}$ where

$T_{j}^{2}=n\left(\overline{\boldsymbol{X}}_{j}-\overline{\overline{\boldsymbol{X}}}\right)^{\prime} S^{-1}\left(\overline{\boldsymbol{X}}_{j}-\overline{\overline{\boldsymbol{X}}}\right), \mathrm{j}=1,2, \ldots$,

Note that the SAS programs given in the next section for the computation of the limits of the $T^{2}$ chart based on the statistics in equation (4) incorporating the various rules are made for the case involving phase 2 .
Implementing Sensitizing Rules on the Conventional Hotelling $T^{2}$ Control Chart: A Nonrigorous Approach

To apply the sensitizing rules on the conventional Hotelling $T^{2}$ chart, first one needs to know the distribution of the $T^{2}$ statistics in equations (1) - (4). If the probability density function of the $T^{2}$ statistic is represented by $f(t)$, then the upper control limit (UCL) of the various sensitizing rules can be determined by solving the following integral:

$\int_{U C L}^{\infty} f(t) d t=p_{A}$.

Here, $p_{A}$, denotes the probability of a point plotting above the UCL. The following four rules will be considered:

The 2-of-2 Rule $\left(\mathrm{S}_{\mathrm{I}}\right)$

This rule signals an out-of-control if two successive points plot above the UCL. For this rule, the in-control ARL $\left(\mathrm{ARL}_{0}\right)$ formula given by Khoo and Quah (2003) is

$\mathrm{ARL}_{0}=\frac{1+g}{g^{2}}$,

where $g$ is the probability of a point falling above the UCL. The following Mathematica 4.0 program can be used to calculate the probability, $g$, based on a fixed $\mathrm{ARL}_{0}$ (denoted by ARL0 in Figure 1) value.

Figure 1. A Mathematica program to compute $g$ for rule $S_{I}$

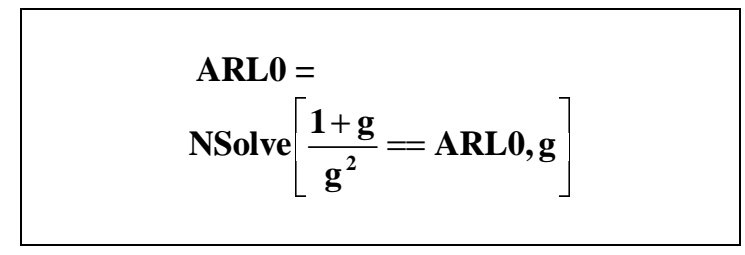

After obtaining the probability, g, equation (5) is used to compute the UCL of this rule. The SAS version 8.02 program in Figure 2 is used to compute the UCL of this rule for the $T^{2}$ chart based on the $T^{2}$ statistics in equations (1) and (3). 
Figure 2. A SAS program to compute the UCL for the $T^{2}$ chart based on equations (1) and (3)

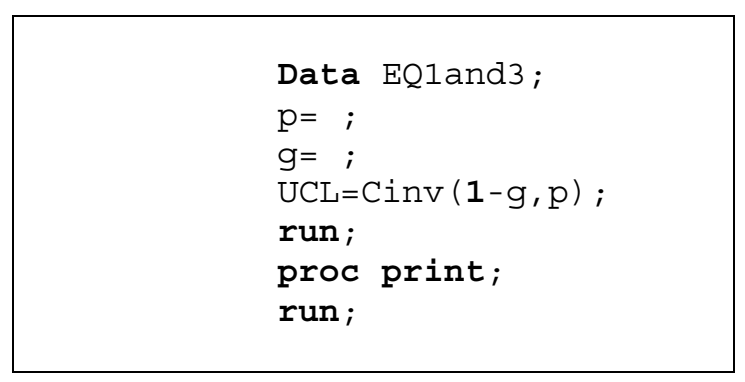

In Figure 2, UCL = Cinv (1-g, p), where Cinv (1-g, p) refers to the $1-g$ percentile of the chi-square distribution with $p$ degrees of freedom. Here, the user needs to enter the desired values of $g$ and $p$, where $\mathrm{p}$ refers to the number of quality characteristics. Note that this program can be used by practitioners to compute the UCL of the 2-of-2 rule for the $T^{2}$ chart of both individual measurements and subgrouped data when the standards $\mu$ and $\Sigma$ are both known.

For the case of individual measurements when both $\mu$ and $\Sigma$ are unknown and are estimated, the limit (UCL) of this rule for the $T^{2}$ chart based on the distribution of the $T_{f}^{2}$ statistics in equation (2), i.e., $T_{f}^{2} \sim$ $\frac{p(m-1)(m+1)}{m(m-p)} F_{p, m-p}$ is computed using the SAS program given in Figure 3.

Figure 3. A SAS program to compute the UCL for the $T^{2}$ chart based on equation (2)

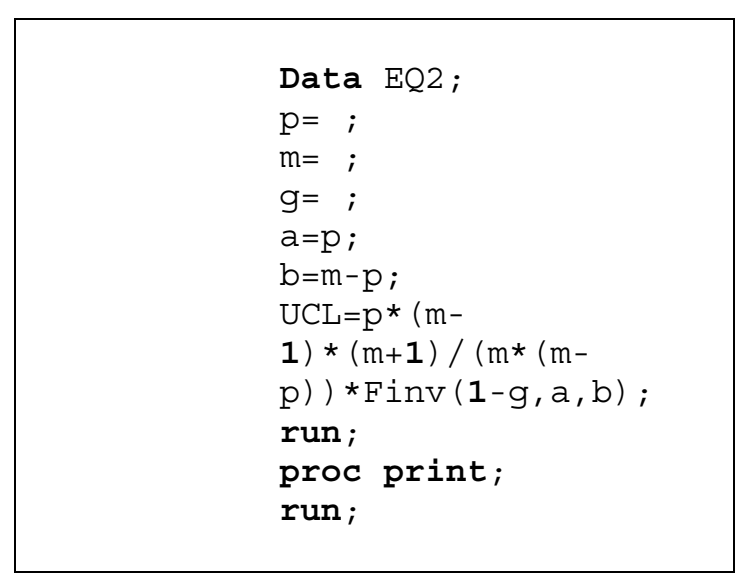

The program shows UCL = $\frac{\mathrm{p}(\mathrm{m}-1)(\mathrm{m}+1)}{\mathrm{m}(\mathrm{m}-\mathrm{p})} \operatorname{Finv}(1-\mathrm{g}, \mathrm{a}, \mathrm{b})$, where $\mathrm{a}=\mathrm{p}$ and $b=m-p$. Note that "Finv $(1-g, a, b)$ " is the $1-g$ percentile of the $F$ distribution with parameters $a$ and $b$. Here, the user needs to enter the values of $p, m$, and $g$ in the program, where the notation $m$ has been defined in the previous section.

Similarly, the limit of this rule for the $T^{2}$ chart involving subgrouped data when the standard values of both $\mu$ and $\Sigma$ are unknown, i.e., the case in equation (4), is calculated using the SAS program in Figure 4. This program deals with the case of monitoring a future production, which is also referred to as phase 2 .

Figure 4. A SAS program to compute the UCL for the $T^{2}$ chart based on equation (4)

\begin{tabular}{|l|} 
Data $\mathrm{EQ} 4 ;$ \\
$\mathrm{p}=;$ \\
$\mathrm{m}=;$ \\
$\mathrm{n}=;$ \\
$\mathrm{g}=;$ \\
$\mathrm{a}=\mathrm{p} ;$ \\
$\mathrm{b}=\mathrm{m} * \mathrm{n}-\mathrm{m}-\mathrm{p}+1 ;$ \\
$\mathrm{UCL}=\mathrm{p} *(\mathrm{~m}+1) *(\mathrm{n}-$ \\
$\mathrm{1}) /(\mathrm{m} * \mathrm{n}-\mathrm{m}-$ \\
$\mathrm{p}+1) * \mathrm{Finv}(1-\mathrm{g}, \mathrm{a}, \mathrm{b}) ;$ \\
run; \\
proc print; \\
run;
\end{tabular}

The 2-of-3 Rule $\left(\mathrm{S}_{\text {II }}\right)$

An out-of-control signal is given by this rule if two of three successive points plot above the UCL. For this case, by solving the corresponding linear system given in Khoo and Quah (2003), the $\mathrm{ARL}_{0}$ formula is found to be

$$
\mathrm{ARL}_{0}=\frac{1+2 g-g^{2}}{g^{2}(2-g)}
$$

where $\mathrm{g}$ denotes the probability of a point falling above the UCL. Figure 5 provides a Mathematica 4.0 program for the computation of the probability $g$ based on a fixed value of 
$\mathrm{ARL}_{0}$.

Figure 5. A Mathematica program to compute $g$ for rule $S_{\text {II }}$

\begin{tabular}{|l} 
ARLO $=$ \\
NSolve $\left[\frac{1+2 g-g^{2}}{g^{2}(2-g)}=\right.$ ARL0, $\left.]\right]$
\end{tabular}

Equation (5) is used to compute the UCL once the value of $g$ is obtained. The UCL of this rule for the $T^{2}$ chart based on the $T^{2}$ statistics in equations (1) and (3) can be computed using the SAS program in Figure 2 while that based on equations (2) and (4) are computed using the SAS programs shown in Figures (3) and (4) respectively.

The Combined 1-of-1 and 2-of-2 Rules ( $S_{\text {III }}$ )

These combined rules signal an out-ofcontrol if either a point plots above $U C L_{U}$ or two successive points plot between $U C L_{L}$ and $U C L_{U}$. The $\mathrm{ARL}_{0}$ formula (Khoo, Quah and Low, 2004) is

$$
\mathrm{ARL}_{0}=\frac{1+g}{g^{2}+h+g h}
$$

where $g$ is the probability that a point falls between $U C L_{L}$ and $U C L_{U}$ while $h$ denotes the probability of a point plotting above $U C L_{U}$. Figure 6 gives a graphical illustration of the limits.

Figure 6. The $U C L_{U}$ and $U C L_{L}$ limits for the combined rules

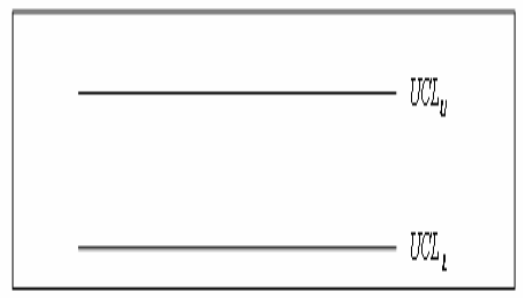

When the $T^{2}$ statistics are based on the formulas in equations (1) and (3), and for an arbitrary value of $p$, the UCLs of the corresponding conventional $T^{2}$ charts for these two cases can be computed using the SAS program given in Figure 2. For this case, $g$ is the desired Type-I error of each of the conventional chart. Similarly, the UCLs of the conventional $T^{2}$ charts based on the $T^{2}$ statistics in equations (2) and (4) can be obtained using the programs in Figures 3 and 4 respectively. After obtaining the UCL value of the $T^{2}$ chart for any of the four cases (equations (1), (2), (3) or (4)) of interest, choose a value of $U C L_{U}$, which is greater than that of the UCL. With this value of $U C L_{U}$, find $h$, the probability of a point falling above $U C L_{U}$. $h$ can be computed using the SAS programs in Figures 7,8 and 9 for cases involving equations (1) and (3), equation (2) and equation (4) respectively.

A brief explanation for the program in Figure 8 will now be given. Because $U C L_{U}=\frac{p(m-1)(m+1)}{m(m-p)} F_{1-h, p, m-p}$, then the $1-h$ percentile of the $F$ distribution with parameters $p$ and $m-p$ is $F_{1-h, p, m-p}=U C L_{U} / \frac{p(m-1)(m+1)}{m(m-p)}$. Note that in Figure $8, F_{1-h, p, m-p}$ is denoted as Finv. Thus, $h=1-P\left(Y<F_{1-h, p, m-p}\right)$ where $Y$ follows an $F$ distribution with parameters $p$ and $m-p$. In Figure 8, this probability is represented by $\mathrm{h}=\mathbf{1}-\operatorname{Probf}($ Finv; $\mathrm{a}, \mathrm{b})$. The SAS program in Figure 9 can be explained in a similar manner.

Once the probability, $h$ is obtained, find the probability $g$ using equation (8) based on the $\mathrm{ARL}_{0}$ value, which is chosen earlier. The Mathematica 4.0 program in Figure 10 can be used in this computation. Next, equation (5) is used to compute the limit $U C L_{L}$ by substituting $p_{A}$ with $g+h$. The computation of $U C L_{L}$ can be made using the SAS programs in Figures 11, 12 and 13 for the $T^{2}$ charts involving equations (1) and (3), equation (2) and equation (4) respectively. The user only needs to enter all the required values in the program which are already known at this stage. 
Figure 7. A SAS program to compute $h$ for the $T^{2}$ chart based on equations (1) and (3)

\begin{tabular}{|l} 
Data EQ1and3; \\
$\mathrm{p}=;$ \\
$\mathrm{UCLu}=;$ \\
$\mathrm{h}=1-$ Probchi $(\mathrm{UCLu}, \mathrm{p}) ;$ \\
run; \\
proc print; \\
run;
\end{tabular}

Figure 8. A SAS program to compute $h$ for the $T^{2}$ chart based on equation (2)

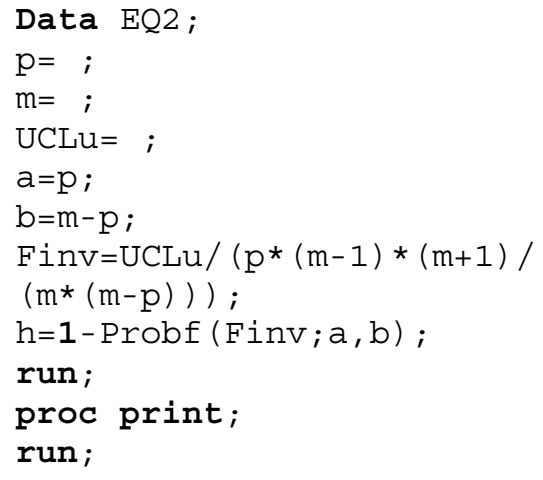

Figure 9. A SAS program to compute $h$ for the $T^{2}$ chart based on equation (4)

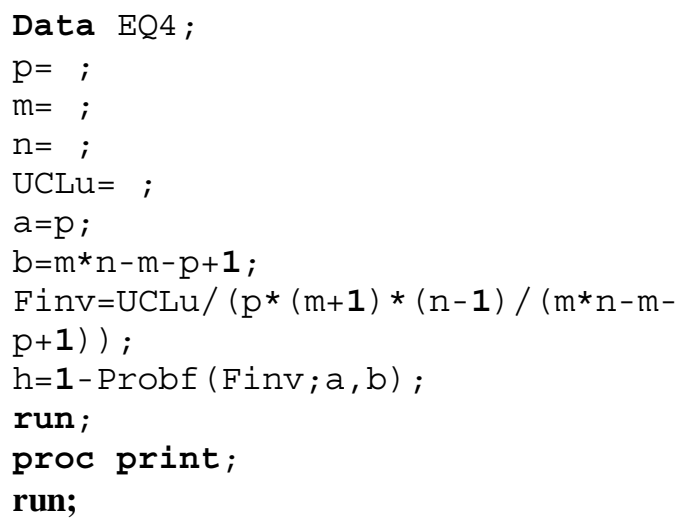

Figure 10. A Mathematica program to compute $g$ for rule $\mathrm{S}_{\mathrm{III}}$

$\mathrm{h}=$

ARLO =

$$
\text { NSolve }\left[\frac{1+g}{g^{2}+h+g h}==\text { ARL0,g }\right]
$$

Figure 11. A SAS program to compute the $U C L_{L}$ for the $T^{2}$ chart based on equations (1) and (3)

\begin{tabular}{ll|} 
Data EQ1and3; \\
$\mathrm{p}=;$ \\
$\mathrm{g}=;$ \\
$\mathrm{h}=;$ \\
$\mathrm{UCLL}=\operatorname{Cinv}(1-\mathrm{g}-\mathrm{h}, \mathrm{p}) ;$ \\
run; \\
proc print; \\
run;
\end{tabular}

Figure 12. A SAS program to compute the $U C L_{L}$ for the $T^{2}$ chart based on equation (2)

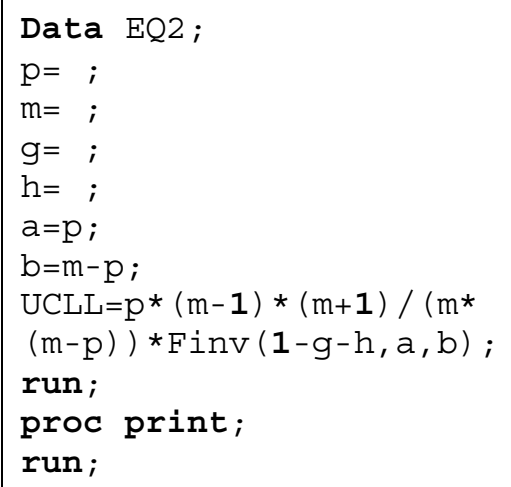


Figure 13. A SAS program to compute the $U C L_{L}$ for the $T^{2}$ chart based on equation (4)

Data $\mathrm{EQ} 4 ;$
$\mathrm{p}=;$
$\mathrm{m}=;$
$\mathrm{n}=;$
$\mathrm{g}=;$
$\mathrm{h}=;$
$\mathrm{a}=\mathrm{p} ;$
$\mathrm{b}=\mathrm{m} * \mathrm{n}-\mathrm{m}-\mathrm{p}+1 ;$
$\mathrm{UCLL}=\mathrm{p}$ (m+1)*(n-1)/(m*n-m-
$\mathrm{p}+1) * \mathrm{Finv}(1-\mathrm{g}-\mathrm{h}, \mathrm{a}, \mathrm{b}) ;$
run;
proc print;
run;

The combined 1-of-1 and 2-of-3 rules $\left(\mathrm{S}_{\mathrm{IV}}\right)$

These combined rules give an out-ofcontrol signal if a point exceeds $U C L_{U}$, or if two of three consecutive points plot between $U C L_{L}$ and $U C L_{U}$ (see Figure 6). Here, the $\mathrm{ARL}_{0}$ formula is (Khoo, Quah and Low, 2004):

$$
\mathrm{ARL}_{0}=\frac{-1+g^{2}+g(-2+h)}{g^{3}+2 g^{2}(-1+h)-h+g(-2+h) h}
$$

In equation (9), $g$ is the probability of a point falling between $U C L_{L}$ and $U C L_{U}$ and $h$ is the probability that a point plots above the $U C L_{U}$.

Similar to the previous combined rules, first choose a $U C L_{U}$ value that is larger than the UCL limit of the conventional $T^{2}$ chart. The UCL of the conventional chart for the four different cases in equations (1), (2), (3) and (4) based on a desired Type-I error can be easily determined using the same approach discussed for rule $\mathrm{S}_{\text {III }}$. Based on a chosen value of $U C L_{U}$, find $h$, the probability of a point plotting above $U C L_{U} . h$ is found from the programs in Figures 7, 8 and 9 for cases involving equations (1) and (3), equation (2) and equation (4) respectively.

After obtaining $h$, find the probability $g$ from equation (9). This is made using the Mathematica 4.0 program in Figure 14. Then, use equation (5) to calculate the limit $U C L_{L}$ by replacing $p_{A}$ with $g+h . U C L_{L}$ can be calculated from the SAS programs in Figures 11, 12 and 13 for the $T^{2}$ charts of equations (1) and (3), equation (2) and equation (4) respectively.

Figure 14. A Mathematica program to compute $g$ for rule $\mathrm{S}_{\mathrm{IV}}$

$$
\begin{aligned}
& \mathbf{h}= \\
& \text { ARL0 = } \\
& \text { NSolve }\left[\begin{array}{l}
\frac{-1+\mathbf{g}^{2}+\mathbf{g}(-\mathbf{2}+\mathbf{h})}{\mathbf{g}^{\mathbf{3}}+2 \mathbf{g}^{2}(-1+h)-h+g(-2+h) h} \\
==\mathbf{A R L 0}, \mathbf{g}
\end{array}\right]
\end{aligned}
$$

Performance Evaluation by Means of a Simulation Study

A simulation study is conducted using Statistical Analysis System (SAS) version 8.02 to evaluate the performances of the sensitizing rules discussed in the previous section. The process is assumed to follow a bivariate normal, $N_{2}(\mu, \Sigma)$ distribution. The in-control mean vector is $\mu_{0}=(0,0)^{\prime}$ while the covariance matrix is $\Sigma=\left(\begin{array}{ll}1 & \rho \\ \rho & 1\end{array}\right)$, where $\rho$ is the correlation coefficient between the two quality characteristics. Due to the directionally invariant property of the Hotelling, $T^{2}$ control chart, the value of $\rho(-1<\rho<1)$ will not have any influence on the performance of the chart. The chart's performance is only dependent on the magnitude of a shift given by $\lambda$. Hence, $\rho=0$ is considered in this simulation study. The magnitude of shifts in the mean vector considered are $\lambda \in\{0,0.25,0.5,1.0,1.5,2.0$, $2.5,3.0,3.5,4.0,5.0\}$ for the case of individual observations and $\lambda \in\{0,0.25,0.30,0.40,0.50$, $0.75,1.00,1.50,2.00,3.00\}$ for the case of subgrouped data where $\lambda^{2}$ is the noncentrality parameter given by

$\lambda^{2}=\left(\mu_{s}-\mu_{0}\right)^{\prime} \Sigma^{-1}\left(\mu_{s}-\mu_{0}\right)$.

Here, $\mu_{s}=(\delta, 0)^{\prime}$ represents the off-target mean vector.

Three in-control ARL values are 
considered, i.e., 500, 750 and 1000. The $T^{2}$ statistics in equations (1) for individual observations and (3) for subgrouped data, are considered because this simulation study is conducted with the assumption that the on-target values of both $\mu_{0}$ and $\Sigma$ are known. The limits of the conventional $T^{2}$ charts and that based on the sensitizing rules for individual observations and subgrouped data with a sample size, $n$, are similar for the same rule if they have a similar in-control ARL because the charts' statistics follow the same distribution, i.e., $\chi_{2}^{2}$. Note that the limits of all the rules are computed using the SAS programs given in the previous section. The values of these limits for the various rules are shown in Tables $1-9$. For the subgrouped data, samples of sizes $n=5$ and 10 are considered. For the combined rules of $\mathrm{S}_{\text {III }}$ and $\mathrm{S}_{\mathrm{IV}}$, the $U C L_{U}$ value of 15 is used for the $T^{2}$ charts in Tables $1-9$. Note that $U C L_{U}=15$ is greater than the limits of the conventional $T^{2}$ charts for all $\mathrm{ARL}_{0}$ values.

The simulation results for the conventional $T^{2}$ chart together with the limits of the $\mathrm{S}_{\mathrm{I}}, \mathrm{S}_{\mathrm{II}}, \mathrm{S}_{\mathrm{III}}$ and $\mathrm{S}_{\text {IV }}$ schemes are shown in Tables $1-9$ where the first three tables are based on individual observations, the next three tables are based on subgrouped data with sample size, $n=5$ and the last three tables are based on subgrouped data with sample size, $n=10$. Tables 1, 4 and 7 have an in-control ARL of 1000, Tables 2, 5 and 8 with $\mathrm{ARL}_{0}$ of 750 while the $\mathrm{ARL}_{0}$ value in Tables 3,6 and 9 is 500 .

The results in all the tables show that the 2-of-2 $\left(\mathrm{S}_{\mathrm{I}}\right)$ and 2-of-3 $\left(\mathrm{S}_{\mathrm{II}}\right)$ rules outperform the conventional $T^{2}$ chart in most cases except for very large magnitude of shifts. For the results of the individual observations in Tables $1-3$, these two sensitizing rules outperform the conventional $T^{2}$ chart for $0<\lambda<3$ and they are only slightly less effective than the latter when $\lambda$ $>3$. For the results of the subgrouped data in Tables $4-9$, the performances of these two rules are superior to the $T^{2}$ chart for $0<\lambda<1$. The performances of these two rules are only slightly inferior to the latter for $\lambda>1$. The combined rules of $\mathrm{S}_{\mathrm{III}}$ and $\mathrm{S}_{\mathrm{IV}}$, however, provide excellent results where they improve the performances of the conventional $T^{2}$ chart for small to moderate magnitude of shifts while maintaining the same sensitivity for large shifts. This is evident from the results in Tables $1-9$. The results show that the performances of the combined rules of $\mathrm{S}_{\mathrm{III}}$ and $\mathrm{S}_{\mathrm{IV}}$ are at par with that of rules $S_{I}$ and $S_{\text {II }}$ for small to moderate magnitude of shifts while slightly outperforming the two latter rules for large shifts.

\section{Examples of Application}

Example 1

This example deals with a small magnitude of shift in the mean vector involving individual measurements. The first 20 bivariate observations are generated from a bivariate normal, $N_{2}\left(\mu_{0}, \Sigma\right)$ distribution, where $\mu_{0}=$ $(0,0)^{\prime}$ is the on target mean vector and $\Sigma=\left(\begin{array}{cc}1 & 0.5 \\ 0.5 & 1\end{array}\right)$ is the covariance matrix. These bivariate observations represent the data from an in-control process. For the o.o.c. case which consists of the next 20 observations, the process is assumed to follow a $N_{2}\left(\mu_{s}, \Sigma\right)$ distribution, where $\mu_{s}=(1,0)^{\prime}$. Note that all the observations are generated using the SAS program. Because $\mu_{0}$ and $\Sigma$ are both known, the $T^{2}$ statistics are computed using equation (1). An in-control ARL of 500 is considered. The values of the $T^{2}$ statistics and variables $X_{1}$ and $X_{2}$ for vector $\mathbf{X}$ $=\left(X_{1}, X_{2}\right)^{\prime}$ from observations $1-40$ are presented in Table 10.

The $T^{2}$ statistics are plotted on the Hotelling $T^{2}$ chart whose limit is computed from the conventional rule using the SAS program in Figure 2 to be UCL $=12.4292$ because $p=2$ and $g=1 / 500$. Besides the conventional approach, an additional o.o.c. test considered is that based on the combined 1-of-1 and 2-of-2 rules, a.k.a., rule $\mathrm{S}_{\mathrm{III}}$. The $U C L_{U}$ of this rule is set as 15 so that $U C L_{U}>\mathrm{UCL}$. 
Table 1. ARL profiles based on $\mathrm{ARL}_{0}=1000$ and $\mu_{s}=(\delta, 0)^{\prime}$ for individual observations

\begin{tabular}{|c|c|c|c|c|c|}
\hline$\lambda=\delta$ & $\begin{array}{c}\text { Conventional } \\
T^{2} \\
(U C L= \\
13.8155) \\
\end{array}$ & $\begin{array}{c}\mathrm{S}_{\mathrm{I}} \\
(U C L= \\
6.87614)\end{array}$ & $\begin{array}{c}\mathrm{S}_{\mathrm{II}} \\
(U C L= \\
7.54488)\end{array}$ & $\begin{array}{c}\mathrm{S}_{\mathrm{III}} \\
\left(U C L_{U}=15 \&\right. \\
\left.U C L_{L}=7.64089\right)\end{array}$ & $\begin{array}{c}\mathrm{S}_{\mathrm{IV}} \\
\left(U C L_{U}=15 \&\right. \\
\left.U C L_{L}=8.29725\right)\end{array}$ \\
\hline 0 & 1001.83 & 996.14 & 998.95 & 1002.31 & 999.65 \\
\hline 0.25 & 817.40 & 817.23 & 805.71 & 805.11 & 801.37 \\
\hline 0.5 & 499.37 & 491.04 & 460.87 & 465.98 & 457.55 \\
\hline 1.0 & 146.70 & 120.35 & 106.26 & 115.68 & 109.06 \\
\hline 1.5 & 44.39 & 31.55 & 27.52 & 30.72 & 28.26 \\
\hline 2.0 & 15.83 & 11.12 & 9.84 & 10.82 & 9.97 \\
\hline 2.5 & 6.83 & 5.33 & 4.89 & 4.86 & 4.57 \\
\hline 3.0 & 3.48 & 3.38 & 3.16 & 2.75 & 2.70 \\
\hline 3.5 & 2.11 & 2.55 & 2.46 & 1.91 & 1.91 \\
\hline 4.0 & 1.50 & 2.21 & 2.18 & 1.48 & 1.49 \\
\hline 5.0 & 1.09 & 2.02 & 2.02 & 1.10 & 1.11 \\
\hline
\end{tabular}

Table 2. ARL profiles based on $\mathrm{ARL}_{0}=750$ and $\mu_{S}=(\delta, 0)^{\prime}$ for individual observations

\begin{tabular}{|c|c|c|c|c|c|}
\hline$\lambda=\delta$ & $\begin{array}{c}\text { Conventional } \\
T^{2} \\
(U C L= \\
13.2401)\end{array}$ & $\begin{array}{c}\mathrm{S}_{\mathrm{I}} \\
(U C L= \\
6.58356)\end{array}$ & $\begin{array}{c}\mathrm{S}_{\mathrm{II}} \\
(U C L= \\
7.24851)\end{array}$ & $\begin{array}{c}\mathrm{S}_{\mathrm{III}} \\
\left(U C L_{U}=15 \&\right. \\
\left.U C L_{L}=7.08929\right)\end{array}$ & $\begin{array}{c}\mathrm{S}_{\mathrm{IV}} \\
\left(U C L_{U}=15 \&\right. \\
\left.U C L_{L}=7.74539\right)\end{array}$ \\
\hline 0 & 749.29 & 750.54 & 750.81 & 753.21 & 751.39 \\
\hline 0.25 & 617.53 & 615.78 & 605.18 & 606.72 & 598.38 \\
\hline 0.5 & 384.40 & 375.83 & 360.34 & 357.75 & 353.88 \\
\hline 1.0 & 117.18 & 98.12 & 86.27 & 91.83 & 85.88 \\
\hline 1.5 & 36.85 & 26.87 & 23.53 & 25.51 & 23.52 \\
\hline 2.0 & 13.56 & 9.98 & 9.06 & 9.34 & 8.52 \\
\hline 2.5 & 6.00 & 5.00 & 4.63 & 4.43 & 4.20 \\
\hline 3.0 & 3.20 & 3.24 & 3.07 & 2.61 & 2.57 \\
\hline 3.5 & 2.01 & 2.49 & 2.45 & 1.86 & 1.85 \\
\hline 4.0 & 1.46 & 2.19 & 2.16 & 1.46 & 1.46 \\
\hline 5.0 & 1.07 & 2.02 & 2.01 & 1.10 & 1.11 \\
\hline
\end{tabular}


Table 3. ARL profiles based on $\mathrm{ARL}_{0}=500$ and $\mu_{s}=(\delta, 0)^{\prime}$ for individual observations

\begin{tabular}{|c|c|c|c|c|c|}
\hline$\lambda=\delta$ & $\begin{array}{c}\text { Conventional } \\
T^{2} \\
(U C L= \\
12.4292) \\
\end{array}$ & $\begin{array}{c}\mathrm{S}_{\mathrm{I}} \\
(U C L= \\
6.16989)\end{array}$ & $\begin{array}{c}\mathrm{S}_{\mathrm{II}} \\
(U C L= \\
6.82846)\end{array}$ & $\begin{array}{c}\mathrm{S}_{\mathrm{III}} \\
\left(U C L_{U}=15 \&\right. \\
\left.U C L_{L}=6.47195\right)\end{array}$ & $\begin{array}{c}\mathrm{S}_{\mathrm{IV}} \\
\left(U C L_{U}=15 \&\right. \\
\left.U C L_{L}=7.1244\right)\end{array}$ \\
\hline 0 & 500.59 & 498.26 & 498.02 & 501.13 & 500.24 \\
\hline 0.25 & 419.81 & 414.91 & 416.32 & 407.17 & 410.95 \\
\hline 0.5 & 265.92 & 259.30 & 247.35 & 248.02 & 243.32 \\
\hline 1.0 & 85.71 & 73.99 & 64.97 & 68.82 & 63.23 \\
\hline 1.5 & 28.42 & 21.68 & 19.36 & 20.41 & 19.07 \\
\hline 2.0 & 10.90 & 8.62 & 7.88 & 7.94 & 7.32 \\
\hline 2.5 & 5.06 & 4.53 & 4.23 & 3.96 & 3.80 \\
\hline 3.0 & 2.81 & 3.05 & 2.93 & 2.46 & 2.45 \\
\hline 3.5 & 1.82 & 2.42 & 2.38 & 1.81 & 1.81 \\
\hline 4.0 & 1.36 & 2.16 & 2.13 & 1.45 & 1.44 \\
\hline 5.0 & 1.06 & 2.01 & 2.01 & 1.10 & 1.11 \\
\hline
\end{tabular}

Table 4. ARL Profiles based on $\mathrm{ARL}_{0}=1000, \mu_{s}=(\delta, 0)^{\prime}$ and $n=5$

\begin{tabular}{cccccc}
\hline & $\begin{array}{c}\text { Conventional } \\
\lambda=\delta\end{array}$ & $\begin{array}{c}\mathrm{S}_{\mathrm{I}} \\
(U C L=\end{array}$ & $\begin{array}{c}\mathrm{S}_{\mathrm{II}} \\
(U C L=\end{array}$ & $\begin{array}{c}\mathrm{S}_{\mathrm{III}} \\
(U C L=\end{array}$ & $\begin{array}{c}\mathrm{S}_{\mathrm{IV}} \\
\left(U C L_{U}=15 \&\right.\end{array}$ \\
& $13.8155)$ & $6.87614)$ & $7.54488)$ & $\left.U C L_{L}=7.64089\right)$ & $\left.U C L_{L}=8.29725\right)$ \\
\hline 0 & 999.15 & 999.87 & 999.81 & 1000.25 & 995.78 \\
0.25 & 436.34 & 427.85 & 401.41 & 402.44 & 391.53 \\
0.30 & 330.97 & 314.71 & 288.86 & 295.56 & 284.64 \\
0.40 & 190.53 & 160.42 & 143.78 & 155.69 & 146.70 \\
0.50 & 108.59 & 84.89 & 74.51 & 81.93 & 78.89 \\
0.75 & 30.22 & 21.23 & 18.58 & 20.22 & 18.96 \\
1.00 & 10.47 & 7.72 & 6.86 & 7.17 & 6.77 \\
1.50 & 2.43 & 2.71 & 2.65 & 2.07 & 2.09 \\
2.00 & 1.25 & 2.07 & 2.06 & 1.25 & 1.26 \\
3.00 & 1.00 & 2.00 & 2.00 & 1.00 & 1.00 \\
\hline
\end{tabular}


Table 5. ARL Profiles based on $\mathrm{ARL}_{0}=750, \mu_{s}=(\delta, 0)^{\prime}$ and $n=5$

\begin{tabular}{cccccc}
\hline & $\begin{array}{c}\text { Conventional } \\
\lambda=\delta\end{array}$ & $\begin{array}{c}\mathrm{S}_{\mathrm{I}} \\
(U C L=\end{array}$ & $\begin{array}{c}\mathrm{S}_{\mathrm{II}} \\
(U C L=\end{array}$ & $\begin{array}{c}\mathrm{S}_{\mathrm{III}} \\
(U C L=\end{array}$ & $\begin{array}{c}\mathrm{S}_{\mathrm{IV}} \\
\left(U C L_{U}=15 \&\right.\end{array}$ \\
& $13.2401)$ & $6.58356)$ & $7.24851)$ & $\left.U C L_{L}=7.08929\right)$ & $\left.U C L_{L}=7.74539\right)$ \\
\hline 0 & 747.90 & 754.01 & 748.27 & 747.18 & 754.15 \\
0.25 & 337.59 & 332.34 & 295.56 & 302.83 & 290.67 \\
0.30 & 257.82 & 239.66 & 221.70 & 228.97 & 224.04 \\
0.40 & 151.95 & 129.44 & 114.90 & 121.92 & 113.32 \\
0.50 & 90.65 & 70.32 & 61.06 & 66.66 & 62.29 \\
0.75 & 25.54 & 18.36 & 16.75 & 17.41 & 15.88 \\
1.00 & 9.04 & 6.97 & 6.22 & 6.34 & 5.97 \\
1.50 & 2.24 & 2.64 & 2.55 & 2.02 & 2.02 \\
2.00 & 1.20 & 2.06 & 2.06 & 1.24 & 1.24 \\
3.00 & 1.00 & 2.00 & 2.00 & 1.00 & 1.00 \\
\hline
\end{tabular}

Table 6. ARL Profiles based on $\mathrm{ARL}_{0}=500, \mu_{s}=(\delta, 0)^{\prime}$ and $n=5$

\begin{tabular}{|c|c|c|c|c|c|}
\hline$\lambda=\delta$ & $\begin{array}{c}\text { Conventional } \\
T^{2} \\
(U C L= \\
12.4292)\end{array}$ & $\begin{array}{c}\mathrm{S}_{\mathrm{I}} \\
(U C L= \\
6.16989)\end{array}$ & $\begin{array}{c}\mathrm{S}_{\mathrm{II}} \\
(U C L= \\
6.82846)\end{array}$ & $\begin{array}{c}\mathrm{S}_{\mathrm{III}} \\
\left(U C L_{U}=15 \&\right. \\
\left.U C L_{L}=6.47195\right)\end{array}$ & $\begin{array}{c}\mathrm{S}_{\mathrm{IV}} \\
\left(U C L_{U}=15 \&\right. \\
\left.U C L_{L}=7.1244\right)\end{array}$ \\
\hline 0 & 504.07 & 499.00 & 503.19 & 498.88 & 503.65 \\
\hline 0.25 & 232.42 & 232.34 & 214.33 & 210.87 & 210.45 \\
\hline 0.30 & 182.91 & 175.59 & 154.77 & 156.20 & 153.86 \\
\hline 0.40 & 110.66 & 94.52 & 85.90 & 89.19 & 82.59 \\
\hline 0.50 & 67.85 & 53.89 & 47.81 & 51.51 & 46.06 \\
\hline 0.75 & 20.25 & 15.06 & 13.70 & 14.18 & 13.10 \\
\hline 1.00 & 7.52 & 6.24 & 5.48 & 5.59 & 5.13 \\
\hline 1.50 & 1.97 & 2.57 & 2.47 & 1.96 & 1.90 \\
\hline 2.00 & 1.15 & 2.05 & 2.05 & 1.25 & 1.26 \\
\hline 3.00 & 1.00 & 2.00 & 2.00 & 1.00 & 1.00 \\
\hline
\end{tabular}


Table 7. ARL Profiles based on $\mathrm{ARL}_{0}=1000, \mu_{s}=(\delta, 0)^{\prime}$ and $n=10$

\begin{tabular}{|c|c|c|c|c|c|}
\hline$\lambda=\delta$ & $\begin{array}{c}\text { Conventional } \\
T^{2} \\
(U C L= \\
13.8155)\end{array}$ & $\begin{array}{c}\mathrm{S}_{\mathrm{I}} \\
(U C L= \\
6.87614)\end{array}$ & $\begin{array}{c}\mathrm{S}_{\mathrm{II}} \\
(U C L= \\
7.54488)\end{array}$ & $\begin{array}{c}\mathrm{S}_{\mathrm{III}} \\
\left(U C L_{U}=15 \&\right. \\
\left.U C L_{L}=7.64089\right)\end{array}$ & $\begin{array}{c}\mathrm{S}_{\mathrm{IV}} \\
\left(U C L_{U}=15 \&\right. \\
\left.U C L_{L}=8.29725\right)\end{array}$ \\
\hline 0 & 995.08 & 1004.27 & 1003.12 & 995.48 & 995.58 \\
\hline 0.25 & 255.15 & 215.16 & 203.18 & 218.26 & 188.25 \\
\hline 0.30 & 164.26 & 140.21 & 124.81 & 141.86 & 120.73 \\
\hline 0.40 & 78.44 & 55.18 & 50.65 & 57.51 & 51.57 \\
\hline 0.50 & 38.28 & 25.30 & 23.30 & 24.94 & 23.69 \\
\hline 0.75 & 8.17 & 6.55 & 6.08 & 6.00 & 5.47 \\
\hline 1.00 & 2.94 & 2.99 & 2.91 & 2.45 & 2.45 \\
\hline 1.50 & 1.13 & 2.03 & 2.04 & 1.18 & 1.18 \\
\hline 2.00 & 1.00 & 2.00 & 2.00 & 1.01 & 1.01 \\
\hline 3.00 & 1.00 & 2.00 & 2.00 & 1.00 & 1.00 \\
\hline
\end{tabular}

Table 8. ARL Profiles based on $\mathrm{ARL}_{0}=750, \mu_{s}=(\delta, 0)^{\prime}$ and $n=10$

\begin{tabular}{|c|c|c|c|c|c|}
\hline$\lambda=\delta$ & $\begin{array}{c}\text { Conventional } \\
T^{2} \\
(U C L= \\
13.2401)\end{array}$ & $\begin{array}{c}\mathrm{S}_{\mathrm{I}} \\
(U C L= \\
6.58356)\end{array}$ & $\begin{array}{c}\mathrm{S}_{\mathrm{II}} \\
(U C L= \\
7.24851)\end{array}$ & $\begin{array}{c}\mathrm{S}_{\mathrm{III}} \\
\left(U C L_{U}=15 \&\right. \\
\left.U C L_{L}=7.08929\right)\end{array}$ & $\begin{array}{c}\mathrm{S}_{\mathrm{IV}} \\
\left(U C L_{U}=15 \&\right. \\
\left.U C L_{L}=7.74539\right)\end{array}$ \\
\hline 0 & 750.00 & 750.34 & 751.20 & 750.69 & 747.47 \\
\hline 0.25 & 185.83 & 176.64 & 148.82 & 172.52 & 149.70 \\
\hline 0.30 & 128.30 & 114.54 & 97.52 & 109.93 & 93.93 \\
\hline 0.40 & 61.94 & 48.94 & 44.05 & 46.01 & 42.01 \\
\hline 0.50 & 32.25 & 23.26 & 18.93 & 21.38 & 19.70 \\
\hline 0.75 & 6.98 & 5.98 & 5.31 & 5.14 & 4.81 \\
\hline 1.00 & 2.76 & 2.97 & 2.88 & 2.35 & 2.36 \\
\hline 1.50 & 1.13 & 2.04 & 2.03 & 1.18 & 1.18 \\
\hline 2.00 & 1.00 & 2.00 & 2.00 & 1.01 & 1.01 \\
\hline 3.00 & 1.00 & 2.00 & 2.00 & 1.00 & 1.00 \\
\hline
\end{tabular}

Table 9. ARL Profiles based on $\mathrm{ARL}_{0}=500, \mu_{s}=(\delta, 0)^{\prime}$ and $n=10$

\begin{tabular}{|c|c|c|c|c|c|}
\hline$\lambda=\delta$ & $\begin{array}{c}\text { Conventional } \\
T^{2} \\
(U C L= \\
12.4292)\end{array}$ & $\begin{array}{c}\mathrm{S}_{\mathrm{I}} \\
(U C L= \\
6.16989)\end{array}$ & $\begin{array}{c}\mathrm{S}_{\mathrm{II}} \\
(U C L= \\
6.82846)\end{array}$ & $\begin{array}{c}\mathrm{S}_{\mathrm{III}} \\
\left(U C L_{U}=15 \&\right. \\
\left.U C L_{L}=6.47195\right)\end{array}$ & $\begin{array}{c}\mathrm{S}_{\mathrm{IV}} \\
\left(U C L_{U}=15 \&\right. \\
\left.U C L_{L}=7.1244\right)\end{array}$ \\
\hline 0 & 505.75 & 502.30 & 501.52 & 505.22 & 499.73 \\
\hline 0.25 & 137.80 & 126.49 & 111.39 & 119.39 & 104.06 \\
\hline 0.30 & 93.79 & 82.06 & 76.72 & 80.06 & 72.60 \\
\hline 0.40 & 45.25 & 34.72 & 34.27 & 35.25 & 32.49 \\
\hline 0.50 & 23.63 & 18.41 & 16.14 & 16.84 & 15.59 \\
\hline 0.75 & 6.16 & 5.35 & 4.76 & 4.46 & 4.33 \\
\hline 1.00 & 2.48 & 2.81 & 2.77 & 2.20 & 2.23 \\
\hline 1.50 & 1.11 & 2.03 & 2.02 & 1.17 & 1.18 \\
\hline 2.00 & 1.00 & 2.00 & 2.00 & 1.01 & 1.01 \\
\hline 3.00 & 1.00 & 2.00 & 2.00 & 1.00 & 1.00 \\
\hline
\end{tabular}


Table 10. The Computed $T_{i}^{2}$ Statistics for Example 1

\begin{tabular}{cccccccc}
\hline Obs. no., & $X_{1}$ & $X_{2}$ & $T_{i}^{2}$ & Obs. no., & $X_{1}$ & $X_{2}$ & $T_{i}^{2}$ \\
\hline$i$ & -0.344 & -1.286 & 1.774 & 21 & 1.585 & 0.361 & 2.762 \\
\hline 1 & -0.882 & 0.150 & 1.245 & 22 & 2.569 & 2.007 & 7.295 \\
2 & -1.990 & 0.545 & 7.125 & 23 & 3.045 & 0.909 & 9.772 \\
3 & -0.343 & -0.067 & 0.132 & 24 & 1.297 & -0.005 & 2.252 \\
4 & -0.800 & -0.358 & 0.643 & 25 & 1.168 & 0.830 & 1.446 \\
5 & -0.620 & 0.364 & 0.990 & 26 & 0.595 & -1.080 & 2.884 \\
6 & -0.004 & -1.041 & 1.440 & 27 & 0.314 & 0.769 & 0.597 \\
7 & 1.479 & -0.131 & 3.197 & 28 & 1.875 & -0.386 & 5.854 \\
8 & -1.082 & -0.478 & 1.175 & 29 & 0.393 & -0.823 & 1.540 \\
9 & 1.549 & -0.602 & 4.927 & 30 & 1.070 & -1.718 & 7.911 \\
10 & -0.317 & -1.128 & 1.353 & 31 & 1.841 & 1.167 & 3.471 \\
11 & 0.408 & 1.464 & 2.282 & 32 & 1.868 & 1.100 & 3.525 \\
12 & 0.639 & 1.037 & 1.094 & 33 & 1.214 & -0.823 & 4.202 \\
13 & -0.879 & -0.080 & 0.945 & 34 & 0.151 & -0.643 & 0.712 \\
14 & -2.294 & 0.286 & 7.997 & 35 & 2.046 & -0.917 & 9.202 \\
15 & 0.060 & 1.066 & 1.434 & 36 & 1.804 & 2.521 & 6.749 \\
16 & -0.586 & 0.127 & 0.578 & 37 & 0.988 & -1.678 & 7.264 \\
17 & -0.818 & 0.279 & 1.300 & 38 & -0.344 & -0.718 & 0.516 \\
18 & -0.600 & 0.610 & 1.464 & 39 & 1.873 & 0.223 & 4.188 \\
19 & 0.127 & -0.209 & 0.115 & 40 & 0.671 & 1.229 & 1.514 \\
20 & & & & & & & \\
\hline
\end{tabular}

Figure 15. The $T^{2}$ chart with limits of the conventional and $\mathrm{S}_{\mathrm{III}}$ rules for example 1

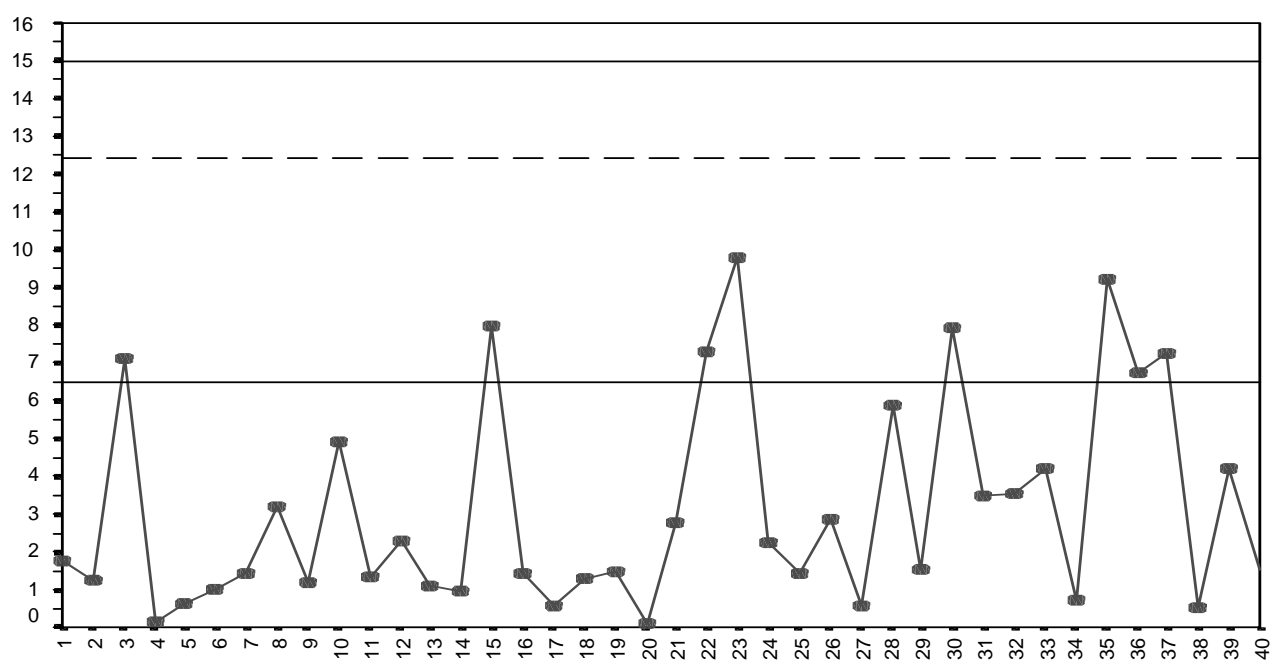

Note: The top parallel line is $\mathrm{UCL}_{\mathrm{u}}$, the slashed parallel line is $\mathrm{UCL}$, and the lower parallel line is $\mathrm{UCL}_{\mathrm{l}}$. 
Table 11. The computed $T_{i}^{2}$ statistics for example 2

\begin{tabular}{cccccccc}
\hline Obs. no., & $X_{1}$ & $X_{2}$ & $T_{i}^{2}$ & Obs. no., & $X_{1}$ & $X_{2}$ & $T_{i}^{2}$ \\
\hline$i$ & -0.344 & -1.286 & 1.774 & 21 & 4.585 & 0.361 & 26.002 \\
2 & -0.882 & 0.150 & 1.245 & 22 & 5.569 & 2.007 & 31.820 \\
3 & -1.990 & 0.545 & 7.125 & 23 & 6.045 & 0.909 & 42.495 \\
4 & -0.343 & -0.067 & 0.132 & 24 & 4.297 & -0.005 & 24.648 \\
5 & -0.800 & -0.358 & 0.643 & 25 & 4.168 & 0.830 & 19.473 \\
6 & -0.620 & 0.364 & 0.990 & 26 & 3.595 & -1.080 & 23.965 \\
7 & -0.004 & -1.041 & 1.440 & 27 & 3.314 & 0.769 & 12.038 \\
8 & 1.479 & -0.131 & 3.197 & 28 & 4.875 & -0.386 & 34.401 \\
9 & -1.082 & -0.478 & 1.175 & 29 & 3.393 & -0.823 & 19.972 \\
10 & 1.549 & -0.602 & 4.927 & 30 & 4.070 & -1.718 & 35.340 \\
11 & -0.317 & -1.128 & 1.353 & 31 & 4.841 & 1.167 & 25.532 \\
12 & 0.408 & 1.464 & 2.282 & 32 & 4.868 & 1.100 & 26.064 \\
13 & 0.639 & 1.037 & 1.094 & 33 & 4.214 & -0.823 & 29.209 \\
14 & -0.879 & -0.080 & 0.945 & 34 & 3.151 & -0.643 & 16.498 \\
15 & -2.294 & 0.286 & 7.997 & 35 & 5.046 & -0.917 & 41.236 \\
16 & 0.060 & 1.066 & 1.434 & 36 & 4.804 & 2.521 & 23.100 \\
17 & -0.586 & 0.127 & 0.578 & 37 & 3.988 & -1.678 & 33.879 \\
18 & -0.818 & 0.279 & 1.300 & 38 & 2.656 & -0.718 & 12.637 \\
19 & -0.600 & 0.610 & 1.464 & 39 & 4.873 & 0.223 & 30.282 \\
20 & 0.127 & -0.209 & 0.115 & 40 & 3.671 & 1.229 & 13.966 \\
\hline
\end{tabular}

Figure 16. The $T^{2}$ chart with limits of the conventional and $\mathrm{S}_{\mathrm{III}}$ rules for example 2

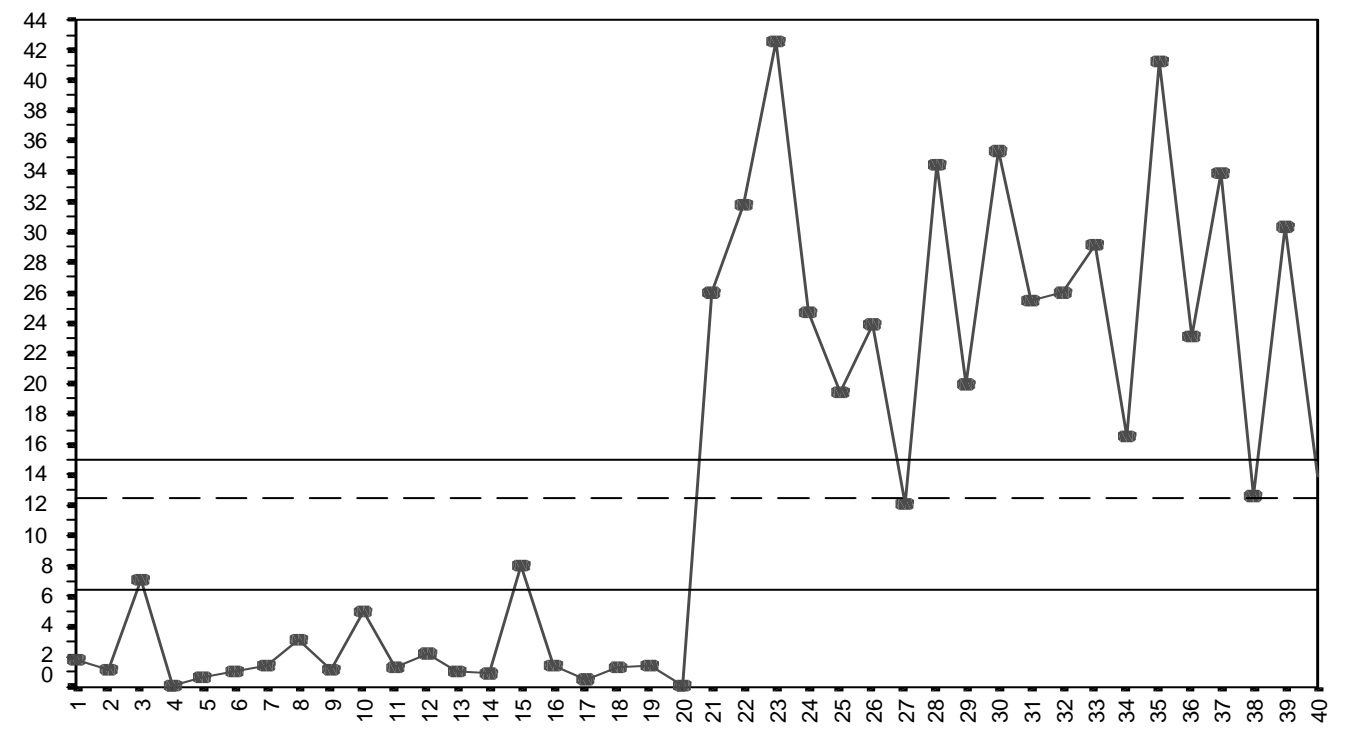

Note: The top parallel line is $\mathrm{UCL}_{\mathrm{u}}$, the slashed parallel line is $\mathrm{UCL}$, and the lower parallel line is $\mathrm{UCL}_{\mathrm{l}}$. 
From the SAS programs in Figures 7 and 11, $U C L_{L}$ is computed to be 6.47195 . The $T^{2}$ statistics are plotted on the $T^{2}$ chart with limit $\mathrm{UCL}=12.4292$ on Figure 15. Additional limits which consist of $U C L_{U}=15$ and $U C L_{L}=$ 6.47195 are drawn on this chart for rule $S_{\text {III }}$. Figure 15 shows that the conventional rule fails to detect a shift in the mean vector. The superiority of rule $S_{\text {III }}$ is obvious in that it detects the first off-target signal at observation 23.

\section{Example 2}

The data in this example, which are generated using the SAS program, involves a shift of a large magnitude in the mean vector. Here, the first 20 bivariate observations are generated from a $N_{2}\left(\mu_{0}, \Sigma\right)$ distribution, where $\mu_{0}=(0,0)^{\prime}$ is the on target mean vector and $\Sigma=\left(\begin{array}{cc}1 & 0.5 \\ 0.5 & 1\end{array}\right)$ is the covariance matrix. This is followed by generating another 20 bivariate observations from a $N_{2}\left(\mu_{s}, \Sigma\right)$ distribution where $\mu_{s}=(4,0)^{\prime}$, to represent the o.o.c. process. The $T^{2}$ statistics are computed from the formula in eq. (1). The values of the $T^{2}$ statistics and quality characteristics $X_{1}$ and $X_{2}$ for observations $1-40$ are given in Table 11 .

Figure 16 gives the $T^{2}$ chart, which consists of the $T^{2}$ statistics plotted on it. The same value of $\mathrm{ARL}_{0}$ considered in Example 1 is used here. The UCL of the conventional $T^{2}$ chart is computed using the same approach described in Example 1 to be 12.4292. Similar to Example 1, rule $S_{\text {III }}$ is also considered. The limits of this rule are obtained using the same approach to be $U C L_{U}=15$ and $U C L_{L}=6.47195$.

An o.o.c. signal is detected at observation 21 by both the conventional and $\mathrm{S}_{\mathrm{III}}$ rules. This example shows that rule $S_{\text {III }}$ has the same sensitivity as the conventional rule in the detection of a large magnitude of shift.

\section{Conclusion}

This article provides a nonrigorous approach of implementing sensitizing rules on a Hotelling control chart. The advantage of the approach presented in this article where the $T^{2}$ statistics do not need to be transformed into normal random variables enable the statistics to be plotted on the original scale so that the incorporation of runs rules can be made on the same conventional chart without having to maintain a separate chart specially designed for plotting the transformed variables which follow a normal distribution. The suggested approach is a remarkable improvement of the earlier works of Khoo and Quah (2003) and Khoo, Quah and Low (2004). The Mathematica and SAS programs provided in this article will certainly serve as useful tools in assisting practitioners in the design and implementation of the various rules.

\section{References}

Apley, D. W. \& Tsung, F. (2002). The autoregressive $T^{2}$ chart for monitoring univariate autocorrelated processes. Journal of Quality Technology, 34, 80 - 96.

Aparisi, F. (1997). Sampling plans for the multivariate $T^{2}$ control chart. Quality Engineering, 10, $141-147$.

Champ, C. W. \& Woodall, W. H. (1987). Exact results for shewhart control charts with supplementary runs rules. Technometrics, 29, 393 - 399 .

Doganaksoy, N., Faltin, F. W., \& Tucker, W. T. (1991). Identification of out of control quality characteristics in a multivariate manufacturing environment. Communications in Statistics: Theory and Methods, 20, 2775 2790.

Holmes, D. S. \& Mergen, A. E. (1995). Identifying the sources for out-of-control signals when the $T^{2}$ control chart is used. Quality Engineering, 8, 137 - 143.

Hotelling, H. (1947). Multivariate quality control, techniques of statistical analysis, Eisenhart, Hastay and Wallis (eds.). New York: McGraw-Hill. 
Khoo, M. B. C., \& Quah, S. H. (2003). Incorporating runs rules into Hotelling $\chi^{2}$ control charts. Quality Engineering, 15, 671 -675 .

Khoo, M. B. C., Quah, S. H., \& Low, H. C. (2004). Powerful rules for the Hotelling's $\chi^{2}$ control chart. Quality Engineering, 17, 139 149.

Klein, M. (2000). Two alternatives to the shewhart $\bar{X}$ control chart. Journal of Quality Technology, 32, $427-431$.

Mason, R. L., Champ, C. W., Tracy, N. D., Wierda, S. J., \& Young, J. C. (1997). Assessment of multivariate process control techniques. Journal of Quality Technology, 29, $140-143$.

Mason, R. L., Chou, Y. M., \& Young, J. C. (2001). Applying Hotelling's $T^{2}$ statistic to batch processes. Journal of Quality Technology, 33, $466-479$.

Mason, R. L., Tracy, N. D., \& Young, J. C. (1995). Decomposition of $T^{2}$ for multivariate control chart interpretation. Journal of Quality Technology, 27, 99 - 108.

Mason, R. L., Tracy, N. D., \& Young, J. C. (1997). A practical approach for interpreting multivariate $T^{2}$ control chart signals. Journal of Quality Technology, 29, 396 - 406.

Montgomery, D. C. (2001). Introduction to statistical quality control (4th ed.). New York: John Wiley and Sons.

Nelson, L. S. (1984). The shewhart control chart: Tests for special causes. Journal of Quality Technology, 16, 237 - 239.
Nedumaran, G. \& Pignatiello, J. J. (1998). Diagnosing signals from $T^{2}$ and $\chi^{2}$ multivariate control charts. Quality Engineering, 10, $657-667$.

Prins, J. \& Mader, D. (1997). Multivariate control charts for grouped and individual observations. Quality Engineering, $10,49-57$.

Runger, G. C. (1996). Projections and the $U^{2}$ multivariate control chart. Journal of Quality Technology, 28, $313-319$.

Runger, G. C., Alt, F. B., \& Montgomery. D. C. (1996). Contributions to a multivariate statistical process control chart signal. Communications in Statistics: Theory and Methods, 25, 2203 - 2213.

Sullivan, J. H., \& Woodall W. H. (1996). A comparison of multivariate control charts for individual observations. Journal of Quality Technology, 28, 398 - 408.

Tracy, N. D., Young, J. C., \& Mason, R. L. (1992). Multivariate control charts for individual observations. Journal of Quality Technology, 24, $88-95$.

Timm, N. H. (1996). Multivariate quality control using finite intersection tests. Journal of Quality Technology, 28, 233 - 243.

Vargas, J. A. (2003). Robust estimation in multivariate control charts for individual observations. Journal of Quality Technology, 35, $367-376$. 